\title{
Comparison of the clinical features and outcomes in two age-groups of elderly patients with atrial fibrillation
}

\author{
Xing-Hui Shao' \\ Yan-Min Yang' \\ Jun Zhu' \\ Han Zhang' \\ Yao Liu' \\ Xin Gao' \\ Li-Tian Yu' \\ Li-Sheng Liu' \\ Li Zhao ${ }^{2}$ \\ Peng-Fei $\mathrm{Yu}^{3}$ \\ Hua Zhang ${ }^{4}$ \\ Qing $\mathrm{He}^{5}$ \\ Xiao-Dan Gu ${ }^{6}$ \\ 'Emergency and Intensive Care \\ Center, Fuwai Hospital, Chinese \\ Academy of Medical Sciences \\ and Peking Union Medical College, \\ Beijing, ${ }^{2}$ Department of Emergency, \\ Fu Xing Hospital, Capital Medical \\ University, Beijing, ${ }^{3}$ Department of \\ Cardiology, Pingdu People's Hospital, \\ Pingdu, ${ }^{4}$ Department of Emergency, \\ Qingdao Municipal Hospital, Qingdao, \\ ${ }^{5}$ Department of Emergency, West \\ China Hospital, Sichuan University, \\ Chengdu, ${ }^{6}$ Department of Emergency, \\ Sixth People's Hospital of Chengdu, \\ Chengdu, People's Republic of China
}

Correspondence: Yan-Min Yang

Emergency and Intensive Care Center,

State Key Laboratory of Cardiovascular

Disease, Fuwai Hospital, National Center for Cardiovascular Diseases, Chinese

Academy of Medical Sciences and Peking Union Medical College, 167 Beilishilu,

Beijing 100037, People's Republic of China $\mathrm{Tel}+86$ I0 $8839847 \mid$

Fax +86 I0 8836459 I

Email yymwin@gmail.com
This article was published in the following Dove Press journal:

Clinical Interventions in Aging

12 August 2014

Number of times this article has been viewed

Background: Atrial fibrillation (AF) disproportionately affects older adults. However, direct comparison of clinical features, medical therapy, and outcomes in AF patients aged 65-74 and $\geq 75$ years is rare. The objective of the present study was to evaluate the differences in clinical characteristics and prognosis in these two age-groups of geriatric patients with AF.

Materials and methods: A total of 1,336 individuals aged $\geq 65$ years from a Chinese AF registry were assessed in the present study: 570 were in the 65- to 74-year group, and 766 were in the $\geq 75$-year group. Multivariable Cox hazards regression was performed to analyze the major adverse cardiac events (MACEs) between groups.

Results: In our population, the older group were more likely to have coronary artery disease, hypertension, previous stroke, cognitive disorder, or chronic obstructive pulmonary disease, and the 65- to 74-year group were more likely to have valvular heart disease, left ventricular systolic dysfunction, or sleep apnea. The older patients had 1.2-fold higher mean $\mathrm{CHADS}_{2}$ (congestive heart failure, hypertension, age $\geq 75$ years, diabetes, stroke) scores, but less probability of being prescribed drugs. Compared with those aged 65-74 years, the older group had a higher risk of death (hazard ratio 2.881, 95\% confidence interval 1.981-4.189; $P<0.001$ ) or MACE (hazard ratio $2.202,95 \%$ confidence interval $1.646-2.945 ; P<0.001)$ at the 1 -year follow-up. In multivariable Cox analyses, secondary AF diagnosis, a history of chronic obstructive pulmonary disease, and left ventricular systolic dysfunction were independent predictors of MACE in the older group.

Conclusion: Patients aged $\geq 75$ years had a worse prognosis than those aged $65-74$ years, and were associated with a higher risk of both death and MACE.

Keywords: atrial fibrillation, geriatric patients, mortality, major adverse cardiac events (MACE)

\section{Introduction}

Atrial fibrillation (AF) is the most common cardiac arrhythmia, and it increases in prevalence with age, ranging from $0.1 \%$ among persons $<55$ years to $9.0 \%$ in adults aged $\geq 80$ years. ${ }^{1,2}$ It is estimated that the current prevalence of AF in the US is 2.3 million, with $75 \%$ aged $>65$ years and $45 \%$ aged $\geq 75$ years. ${ }^{3}$ According to the American College of Cardiology (ACC)/American Heart Association (AHA)/European Society of Cardiology (ESC) guidelines, antithrombotic therapy is the first recommended for AF patients. ${ }^{4,5}$ Nevertheless, using anticoagulants in the elderly is a great challenge, because the risks of stroke from AF and hemorrhage from anticoagulation both increase with age. ${ }^{6,7}$ Moreover, older patients with AF more frequently have coexisting concomitant conditions, such as heart failure or thromboembolism, which predispose them to worse 
prognosis. With the exacerbation of the aging population, AF in the elderly will increase as a health problem and represent both a management burden and cost burden for physicians, patients, and health care systems. ${ }^{8-10}$

It is well recognized that stroke prevention is central to the management of AF, and advanced age has been identified as an independent predictor for stroke in various stroke risk-stratification schemes. ${ }^{11}$ A recently study, based on a large cohort of AF patients, demonstrated that the relative hazard for increased stroke and thromboembolism was 2.97-fold in the 65- to 74-year age-group and 5.28-fold for age $\geq 75$ years, with age $<65$ years as reference. ${ }^{12}$ In addition, the 2012 focused update of the ESC guideline strongly recommends the $\mathrm{CHA}_{2} \mathrm{DS}_{2}$-VASc (congestive heart failure, hypertension, age $\geq 75$ years, diabetes, stroke, vascular disease, age 65-74 years, sex category) score to extend to the most widely used $\mathrm{CHADS}_{2}$ (congestive heart failure, hypertension, age $\geq 75$ years, diabetes, stroke) score by giving 2 points to age $\geq 75$ years, and 1 point to age $65-74$ years. ${ }^{13}$ This suggested that AF patients aged $\geq 75$ years were associated with higher risks for stroke compared with those aged 65-74 years. Nonetheless, direct comparison of the clinical features, medical therapy, and major end-point events in AF patients aged 65-74 years and $\geq 75$ years has not been illustrated yet. The objective of this study was to evaluate the differences in clinical characteristics and prognosis in these two age-groups of geriatric patients with AF.

\section{Materials and methods}

The Chinese AF registry was a multicenter, prospective, observational study with a 1-year follow-up. Twenty representative centers from different areas participated (see "Participating investigators" section). The registry enrolled patients who presented to an emergency department with AF or atrial flutter from November 2008 to October 2011, either as the primary or secondary diagnosis. The main objective was to evaluate the clinical characteristics, medical treatments, risk factors, and long-term outcomes in Chinese patients with AF. Among the included patients, 1,336 individuals aged $\geq 65$ years were assessed. According to the design of the present study, the population was divided into two groups: age $65-74$ years and $\geq 75$ years.

Patients were identified using electronic hospital databases recording emergency department (ED) diagnosis, review of electrocardiograms and telemetry recording from the ED, and direct screening by research staff. For each patient, demographics, medical history, and clinical variables were collected at baseline. For blood pressure (BP) and heart rate, initial data at registration were documented. Body mass index (BMI; weight $[\mathrm{kg}] /$ height $[\mathrm{m}]^{2}$ ) was calculated using the weight and height measured at enrollment. The definitions of AF types were in accordance with ACC/AHA/ESC 2006 guidelines for AF. We combined persistent $\mathrm{AF}$ and permanent $\mathrm{AF}$ as sustained AF. All treatment decisions were left to the discretion of the treating physician.

Follow-up was carried out at 1 year from time of enrollment by telephone interview. The main study outcomes included all-cause mortality, stroke, non-central nervous system (CNS) systemic embolism and major bleed. Primary stroke included all strokes - ischemic and hemorrhagic - that were associated with focal neurological symptoms lasting more than 24 hours. Non-CNS systemic embolism was defined as the occurrence of myocardial infarction, pulmonary embolism, or peripheral embolism. Major bleeding was defined as fatal bleeding and/or symptomatic bleeding in a critical area or organ, such as intracranial, intraspinal, intraocular, retroperitoneal, intra-articular or pericardial, or intramuscular with compartment syndrome, and/or bleeding causing a fall in hemoglobin level of $20 \mathrm{~g} / \mathrm{L}(1.24 \mathrm{mmol} / \mathrm{L})$ or more, or leading to transfusion of two or more units of whole blood or red cells. Major adverse cardiac events (MACEs) included all-cause mortality, stroke, non-CNS systemic embolism, and major bleeding.

The study was approved by the ethics committees of each institution, and all the patients enrolled in the registry gave written consent for study participation. Data were collected on a standardized case-report form through searching medical records and patient interviews from each center. The forms were sent to Fuwai Hospital by fax at the earliest opportunity. Using a validation plan integrated in the data-entry software, data were checked for missing or contradictory entries and values out of the normal range. Additional edit checks were performed by the staff in Fuwai Hospital.

\section{Statistical analysis}

Categorical variables were expressed as frequencies and percentages, and normally distributed continuous variables were presented as means with standard deviation. Different patients' strata were compared with two-sided Student's $t$-test for continuous variables, and $\chi^{2}$ tests for categorical variables. For the main outcomes, time to the first event was recorded, whereas other events were censored. Cox proportional hazard regression analyses were used to identify the association of the main outcomes between 
age-groups and the independent predictors of all-cause mortality and MACEs in each group, as well as the interactions between age-groups and each baseline covariate. The model included sex, primary diagnosis of AF, history of myocardial infarction, coronary artery disease, heart failure, hypertension, diabetes, previous stroke/transient ischemic attack, history of left ventricular systolic dysfunction, left ventricular hypertrophy, chronic obstructive pulmonary disease, hyperthyroidism, valvular heart diseases, prior major bleeding, smoking, $\mathrm{CHADS}_{2}$-score stratification, and medications (including angiotensin-converting enzyme [ACE] inhibitors or angiotensin II-receptor blockers, $\beta$-blockers, calcium-channel blockers, digoxin, diuretics, anticoagulants, aspirin or platelet inhibitors, and lipid-lowering drugs). Kaplan-Meier curves were constructed for time to event and were compared by logrank test. The data were analyzed with SPSS 17.0 (SPSS, Chicago, IL, USA), and a two-sided $P$-value $<0.05$ was considered statistically significant.

\section{Results}

A total of 2,016 AF patients were enrolled in the Chinese AF registry. Of the whole cohort, 1,336 participants (age $\geq 65$ years) entered the present study: 570 in the 65 - to 74 -year group, and 766 in the $\geq 75$-year group. Figure 1 shows the trial profile.

Patient demographics, past medical history, and medication during the ED visit of the two groups are shown in Table 1. At enrollment, more patients presented to EDs with AF as a secondary diagnosis in the $\geq 75$-year group. Compared with the 65- to 74-year group, the older group had a lower BMI and diastolic BP but a higher systolic BP. The mean $\mathrm{CHADS}_{2}$ score was 1.2-fold higher in the $\geq 75$-year group than in the 65- to 74-year group. Coronary artery disease, hypertension, previous stroke/transient ischemic attack, cognitive disorder, and chronic obstructive pulmonary disease (COPD) were more represented in the older group, while sleep apnea, smoking, history of left ventricular systolic dysfunction, and valvular heart disease were more prevalent in the 65- to 74-year group.

During hospitalization, diuretics, ACE inhibitors, digoxin, and oral anticoagulants were all given significantly more often in patients aged 65-74 years. Warfarin prescription by $\mathrm{CHADS}_{2}$-score stratification between groups is shown in Figure 2. There was no difference between the groups with regard to angiotensin II-receptor blockers, $\beta$-blockers,

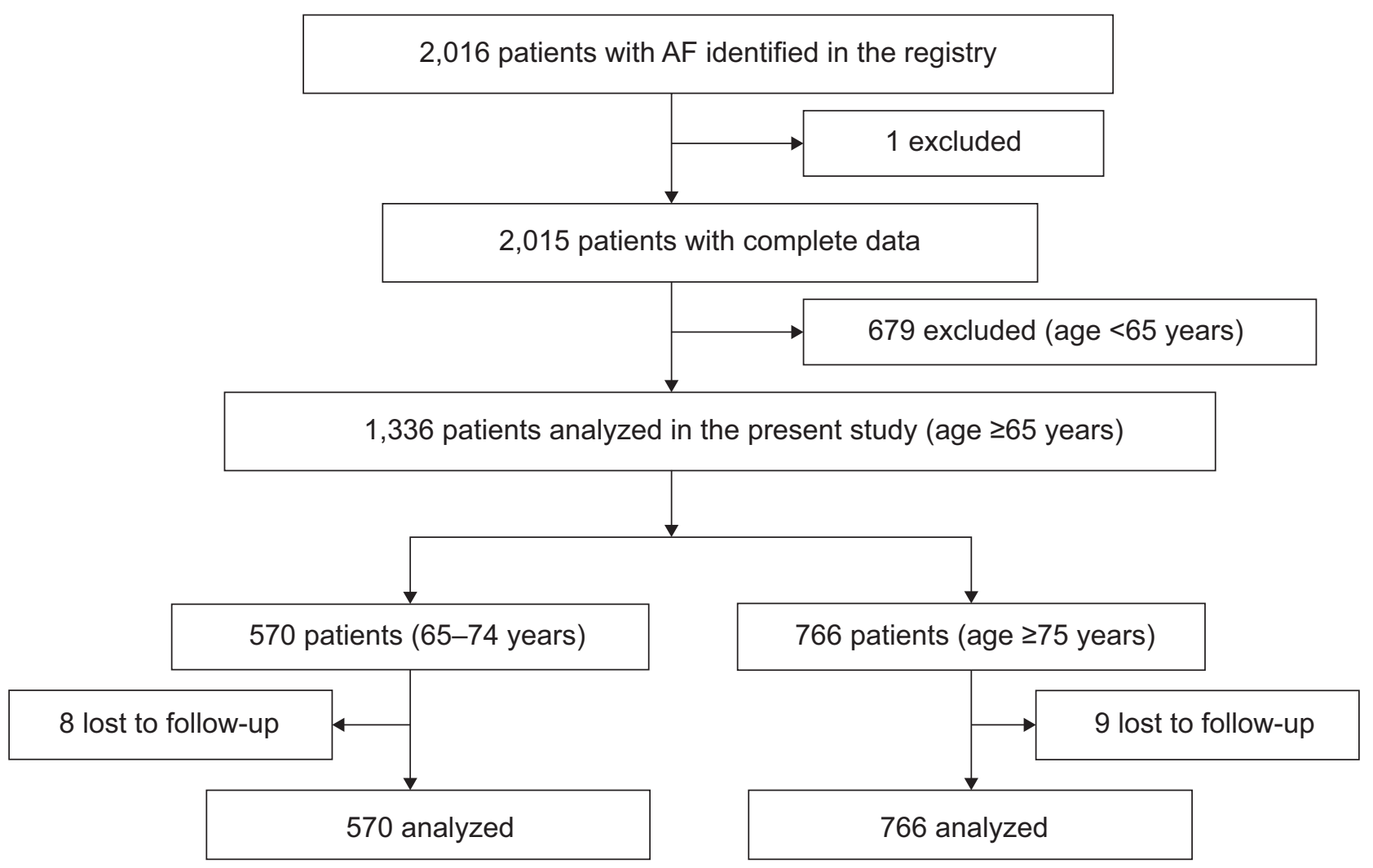

Figure I Trial profile. Abbreviation: $A F$, atrial fibrillation. 
Table I Baseline characteristics by age-group

\begin{tabular}{|c|c|c|c|}
\hline \multirow[t]{2}{*}{ Characteristic } & \multicolumn{2}{|c|}{ Age-group (years) } & \multirow[t]{2}{*}{$P$-value } \\
\hline & $65-74(n=570)$ & $\geq 75(n=766)$ & \\
\hline Mean age (years), mean (SD) & $70.18(2.708)$ & $80.76(4.657)$ & - \\
\hline Female sex, n (\%) & $308(54.0)$ & $436(56.9)$ & 0.316 \\
\hline BMI $\left(\mathrm{kg} / \mathrm{m}^{2}\right)$, mean $(\mathrm{SD})$ & $23.79(3.59)$ & $23.08(3.38)$ & $<0.001$ \\
\hline Systolic BP (mmHg), mean (SD) & 133.75 (22.92) & | $36.82(23.26)$ & 0.016 \\
\hline Diastolic BP (mmHg), mean (SD) & $81.39(14.89)$ & $79.70(15.04)$ & 0.042 \\
\hline Heart rate (beats/minute), mean (SD) & 99.01 (27.34) & $101.36(29.12)$ & 0.135 \\
\hline Secondary AF diagnosis, n (\%) & $321(56.3)$ & $508(66.3)$ & $<0.001$ \\
\hline Sustained AF, n (\%) & $399(70.0)$ & $533(72.2)$ & 0.393 \\
\hline Mean $\mathrm{CHADS}_{2}$ score*, mean (SD) & $1.56(1.20)$ & $2.76(1.25)$ & $<0.00 \mathrm{I}$ \\
\hline Low (score 0 or I), n (\%) & $28 I(56.4)$ & $104(14.6)$ & $<0.001$ \\
\hline Intermediate (score 2), n (\%) & 114 (22.9) & $244(34.2)$ & - \\
\hline High (score 3-6), n (\%) & $103(20.7)$ & $365(5 \mid .2)$ & - \\
\hline \multicolumn{4}{|l|}{ Medical history } \\
\hline Myocardial infarction, n (\%) & $42(7.4)$ & $73(9.5)$ & 0.169 \\
\hline Coronary artery disease, $\mathrm{n}(\%)$ & $263(46.1)$ & $44 \mid(57.6)$ & $<0.00 \mathrm{I}$ \\
\hline Heart failure, n (\%) & $220(38.6)$ & $27 \mid(35.4)$ & 0.229 \\
\hline Hypertension, n (\%) & $353(61.9)$ & $523(68.3)$ & 0.017 \\
\hline LVH, n (\%) & $110(19.3)$ & $|2|(\mid 5.8)$ & 0.108 \\
\hline Stroke/TIA, n (\%) & III (19.5) & $196(25.6)$ & 0.009 \\
\hline Sleep apnea, n (\%) & $25(4.4)$ & $13(1.7)$ & 0.004 \\
\hline Smoking, n (\%) & 134 (23.5) & $133(17.4)$ & 0.006 \\
\hline LVSD, n (\%) & $127(22.3)$ & $134(17.5)$ & 0.031 \\
\hline Cognitive disorder, n (\%) & $8(1.4)$ & $30(3.9)$ & 0.007 \\
\hline COPD, n (\%) & $72(12.6)$ & $140(\mid 8.3)$ & 0.005 \\
\hline Diabetes, n (\%) & $95(16.7)$ & $157(20.5)$ & 0.077 \\
\hline Hyperthyroidism, n (\%) & $16(2.8)$ & $14(1.8)$ & 0.265 \\
\hline Valvular heart disease, $\mathrm{n}(\%)$ & $72(12.6)$ & $52(6.8)$ & $<0.001$ \\
\hline Major bleeding, n (\%) & $12(2.1)$ & $17(2.2)$ & 1.0 \\
\hline \multicolumn{4}{|l|}{ Medication } \\
\hline Diuretics, n (\%) & $255(44.7)$ & $294(38.4)$ & 0.021 \\
\hline CCB, n (\%) & $185(32.5)$ & $264(34.5)$ & 0.447 \\
\hline$\beta$-blocker, n (\%) & $291(5 I .1)$ & $395(46.9)$ & 0.135 \\
\hline ACE inhibitor, $n(\%)$ & I77 (3I.I) & $179(23.4)$ & 0.002 \\
\hline ARB, n (\%) & $|2|(2 \mid .2)$ & $177(23.1)$ & 0.426 \\
\hline Digoxin, n (\%) & $209(36.7)$ & $222(29.0)$ & 0.003 \\
\hline Oral anticoagulant, n (\%) & $104(18.2)$ & 85 (II.I) & $<0.00 \mathrm{I}$ \\
\hline ASA or platelet inhibitor, n (\%) & $380(66.7)$ & $507(66.2)$ & 0.861 \\
\hline Lipid-lowering medication, $\mathrm{n}$ (\%) & $165(28.9)$ & $25 I(32.8)$ & 0.152 \\
\hline
\end{tabular}

Notes: Data are expressed as $\mathrm{n}(\%)$ or mean (standard deviation [SD]). *Data excluded those with valvular heart disease. For the risk-stratification scheme for atrial fibrillation, a score of 0-6 was derived based on the following factors: congestive heart failure ( $\mid$ point), hypertension ( $\mid$ point), age $>75$ years ( $\mid$ point), diabetes mellitus ( $\mid$ point), and previous stroke or TIA (2 points).

Abbreviations: BMI, body mass index; BP, blood pressure; AF, atrial fibrillation; CHADS, congestive heart failure, hypertension, age $\geq 75$ years, diabetes, stroke; LVH, left ventricular hypertrophy; TIA, transient ischemic attack; LVSD, left ventricular systolic dysfunction; COPD, chronic obstructive pulmonary disease; CCB, calcium-channel blocker; ACE, angiotensin-converting enzyme; ARB, angiotensin II-receptor blocker; ASA, acetylsalicylic acid (aspirin).

calcium-channel blockers, antiplatelet inhibitors, or lipidlowering medication (Table 1).

We had 1 year's follow-up data available for $98.8 \%$ $(n=1,992)$ of the baseline population, including 562 in the 65 - to 74-year age-group and 757 in the $\geq 75$-year age-group (Figure 1). Table 2 shows the major end-point events. In timeto-first-event analyses, there were 342 MACEs during the follow-up period, of which all-cause mortality represented 233 cases. The older group had a 1.4-fold increased unadjusted risk of MACEs than the 65- to 74-year group, which persisted after adjusting for differences in baseline characteristics. As with MACEs, the unadjusted risk of allcause mortality was 2.1 -fold increased in the $\geq 75$-year group than in the 65- to 74-year group, remaining significant after adjusting for baseline covariates. Of note, the unadjusted risk of stroke alone was 0.55 -fold higher in the $\geq 75$-year group than in 65- to 74-year group, whereas the differences were not significant after adjustment for confounders. There was a trend for higher risk of non-CNS systemic embolism and lower risk of major bleeding in the older group than 


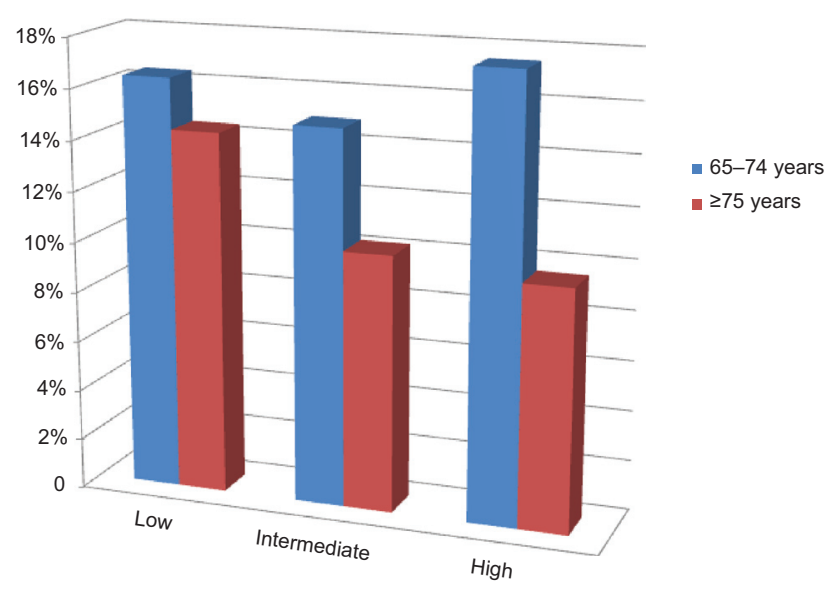

Figure 2 Anticoagulation rate by $\mathrm{CHADS}_{2}$-score stratification in 65- to 74-year-old (blue) and $\geq 75$-year-old (red) groups.

Abbreviation: CHADS, congestive heart failure, hypertension, age $\geq 75$ years, diabetes, stroke.

in the 65- to 74-year group, which did not reach statistical significance. Kaplan-Meier cumulative hazard curves of the events are shown in Figure 3.

In age-stratified multivariable Cox analyses, we identified the predictors for all-cause mortality and MACEs in both groups (Table 3). In the 65- to 74-year group, use of digoxin was an independent risk factor of all-cause mortality. In the $\geq 75$-year group, patients with $\mathrm{AF}$ as a secondary diagnosis and a history of COPD were significantly associated with a higher mortality rate. Also, secondary AF diagnosis, a history of COPD, and left ventricular systolic dysfunction were independent predictors of MACEs in the older group. To gain further insights into the hazard ratios for the events, we tested for interactions between age and the baseline variables. For all-cause death, interactions between age-group and sex and between age-group and use of digoxin were statistically significant.

\section{Discussion}

To the best of our knowledge, this is the first study to directly compare the clinical profile and long-term outcomes between patients aged $65-74$ years and $\geq 75$ years with AF. The present analysis indicated that patients aged $\geq 75$ years had a worse prognosis compared with the 65- to 74-year group, regardless of the risk profile and medication. Patients aged $\geq 75$ years with $\mathrm{AF}$ as a secondary diagnosis were independently associated with higher risk of MACEs.

In multivariable Cox analysis, we observed a 1.2-fold higher risk for MACEs in the older group, which suggested that being aged $\geq 75$ years was an independent predictor for major adverse events compared with the 65- to 74-year group. As is known, the 2012 focused update of the ESC guideline strongly recommended the $\mathrm{CHA}_{2} \mathrm{DS}_{2}$-VASc score, which assigns 1 point for age 65-74 years and 2 points for age $\geq 75$ years, to complement the traditional $\mathrm{CHADS}_{2}$-score risk factors for stroke prevention in AF patients. ${ }^{13}$ That means that patients aged $\geq 75$ years have a higher risk of suffering a stroke than the 65- to 74-year group. Here, our results extend the concept to MACEs. Although the risk of stroke did not reach statistical significance after adjustment for baseline characteristics in the present study $(10.6 \%$ versus $6.9 \%$, unadjusted hazard ratio 1.553 [95\% confidence interval 1.059-2.278], adjusted hazard ratio 1.557 [95\% confidence interval 0.980-2.474]), we conjecture small sample size and the combination analysis of ischemic stroke and hemorrhagic stroke might be possible reasons.

Our study demonstrated a notable age-related difference in baseline variables in patients aged $\geq 65$ years. More than a decade ago, the analysis from the Framingham study illustrated that diastolic pressure tends to decline as systolic pressure levels off at older ages. ${ }^{14} \mathrm{We}$ confirmed this in the present study. In our population, the older group were more likely to have coronary artery disease, hypertension, previous stroke, cognitive disorder, or COPD, and the 65- to 74-year group were more likely to have valvular heart disease, left ventricular systolic dysfunction, or sleep apnea. Also, compared with the 65- to 74-year group, the older patients were less probably being prescribed with drugs, such as ACE inhibitors, diuretics, digoxin, and warfarin. These factors might partly explain the difference in prognosis between the groups in terms of more comorbidities

Table 2 Major outcomes during follow-up

\begin{tabular}{|c|c|c|c|c|c|c|c|}
\hline \multirow[t]{2}{*}{ Outcomes } & \multicolumn{2}{|c|}{ Age-group (years) } & \multirow{2}{*}{$P$-value } & \multirow{2}{*}{$\frac{\text { Univariate analysis }}{\text { HR }(95 \% \mathrm{Cl})}$} & \multirow[t]{2}{*}{$P$-value } & \multirow{2}{*}{$\frac{\text { Multivariate analysis }}{\text { HR }(95 \% \mathrm{Cl})}$} & \multirow[t]{2}{*}{$P$-value } \\
\hline & $\begin{array}{l}65-74(n=562), \\
n(\%)\end{array}$ & $\begin{array}{l}\geq 75(n=757), \\
n(\%)\end{array}$ & & & & & \\
\hline All-cause mortality & $49(8.7)$ & $184(24.3)$ & $<0.001$ & $3.052(2.227-4.183)$ & $<0.001$ & $2.88 I(1.98 I-4.189)$ & $<0.001$ \\
\hline Stroke & $39(6.9)$ & $80(10.6)$ & 0.027 & $1.553(1.059-2.278)$ & 0.024 & $1.557(0.980-2.474)$ & 0.061 \\
\hline Non-CNS systemic embolism & $2(0.4)$ & $9(1.2)$ & 0.130 & $3.373(0.725-15.674)$ & 0.121 & $2.766(0.426-17.983)$ & 0.287 \\
\hline Major bleeding & $7(1.2)$ & $5(0.7)$ & 0.380 & $0.528(0.167-1.672)$ & 0.277 & $0.492(0.101-2.403)$ & $0.38 \mathrm{I}$ \\
\hline MACE & $89(15.8)$ & $253(33.5)$ & $<0.001$ & $2.363(1.856-3.009)$ & $<0.001$ & $2.202(1.646-2.945)$ & $<0.001$ \\
\hline
\end{tabular}

Abbreviations: $\mathrm{HR}$, hazard ratio; $\mathrm{Cl}$, confidence interval; CNS, central nervous system; MACE, major adverse cardiac event. 

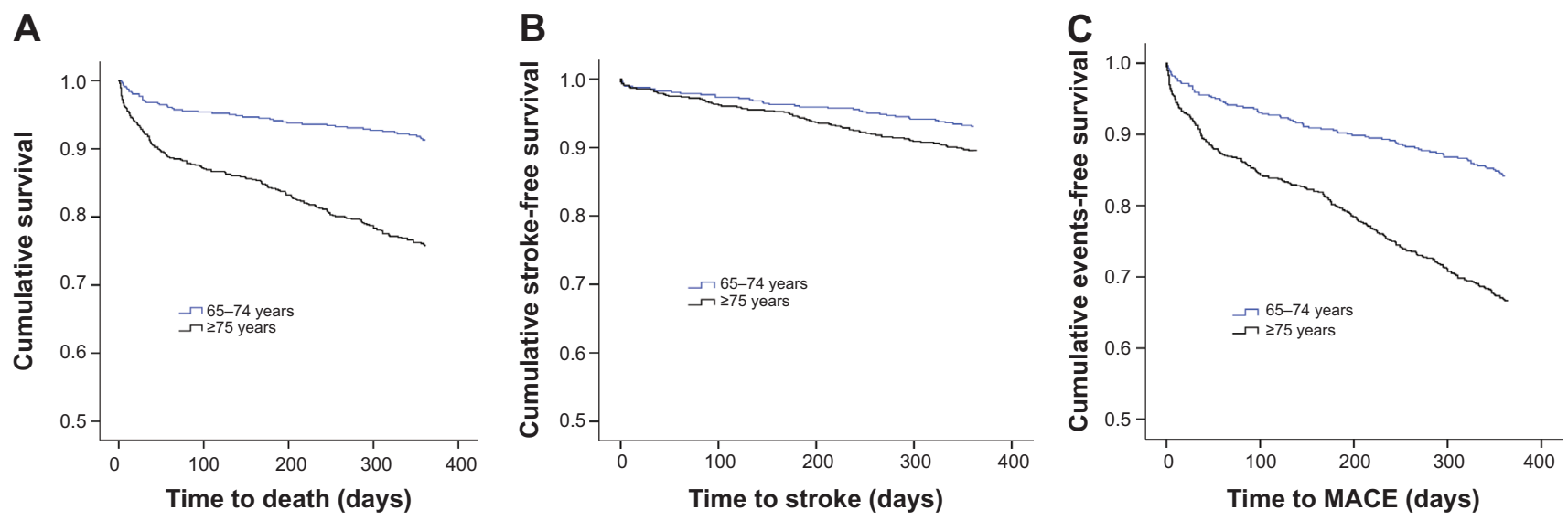

Figure 3 Kaplan-Meier plots of time to events.

Notes: (A) All-cause death (log-rank $P<0.001$ ); (B) stroke (log-rank $P=0.023$ ); (C) major adverse cardiac event (MACE; log-rank $P<0.00 \mathrm{I})$.

with less medication. It is worth mentioning that although we presented a 1.2-point higher mean $\mathrm{CHADS}_{2}$ score in the older group, the effective difference in the $\mathrm{CHADS}_{2}$ score was 0.2 points, since age $\geq 75$ years gave 1 point to the older patients.

The anticoagulation rate in the present study was $18.2 \%$ in the 65 - to 74 -year group and $11.1 \%$ in the $\geq 75$-year group $(P<0.001)$. Moreover, in the older group, the proportion of warfarin prescription decreased as the $\mathrm{CHADS}_{2}$ score increased (Figure 2). Despite its benefits, the underuse of warfarin is quite common for the elderly. ${ }^{15}$ In a single US institution, warfarin was prescribed at discharge to $75 \%$ of those aged $65-69$ years, $59 \%$ of those aged $70-79$ years, $45 \%$ of those aged $80-89$ years, and $24 \%$ of those aged $\geq 90$ years. ${ }^{6}$ For geriatric patients with AF, treatment with anticoagulation agents is a great challenge, because the older patients that will probably benefit most from anticoagulation therapy are also at the highest risk of bleeding complication. ${ }^{16}$ Guo et al declared that patients aged 90 years were five times more likely to develop diseases with risks of both hemorrhage and thromboembolism compared with those aged 80 years. ${ }^{17} \mathrm{In}$ clinical practice, this confusion might have an impact on decision making regarding antithrombotic therapy, and currently less than one-third of elderly receive warfarin. ${ }^{18}$ Nonetheless, recent large trials have proven that novel oral anticoagulants have a greater net clinical benefit than warfarin, including in subgroups of older patients. ${ }^{19-21}$ We expect a promising application of novel oral anticoagulants for elderly patients, and also prospective, randomized, controlled trials of newer agents in the elderly population with $\mathrm{AF}$ are needed.

In this study, we found that secondary AF diagnosis and a history of COPD were independent risk factors for all-cause death and MACEs in the $\geq 75$-year group, rather than in the 65- to 74-year group. It is suggested that concomitant diseases, especially COPD, were independently associated with adverse clinical events in older individuals. COPD is common in the elderly, particularly those aged $\geq 75$ years. ${ }^{22}$ Pathological changes in patients with COPD may lead to a high relative risk for occurrence or development of $\mathrm{AF}^{23}$ The frequent coexistence of $\mathrm{AF}$ and COPD in the elderly may complicate the treatment of both conditions, exacerbate the diseases, and ultimately jeopardize health outcomes, resulting in a heavy economic burden. Based on these considerations, we put forward the recommendation that management of the underlying COPD exacerbation should take priority in older patients with AF.

The limitation of our study was that it was a hospitalbased study, which might not reflect the status of the general community. Moreover, subjects in the present analysis were derived from the Chinese AF registry. Due to the nature of an observational study, there may exist selection bias. However, we encouraged all participating centers to recruit consecutive patients so as to minimize the bias. Finally, we had no echocardiography data on admission, and this might have had an influence on distinguishing the relationship between cardiac function and major end-point events.

\section{Conclusion}

In geriatric patients with $\mathrm{AF}$, there were apparent differences between the 65 - to 74 -year group and the $\geq 75$-year group. Patients aged $\geq 75$ years had a worse prognosis than the 65- to 74-year group and were associated with higher risks of both death and MACEs. 







\section{Participating investigators}

Jun Zhu (Beijing), Yan-Min Yang (Beijing), Chun-Sheng Li (Beijing), Xiao-Juan Bai (Shenyang), Fang Zhang (Qingdao), Jun-Xia Li (Shijiazhuang), Yi-Ming Lu (Shanghai), Han-Sheng Tang (Wuhan), Ji-Yuan Han (Wuhan), Qing He (Chengdu), Hong-Ke Zeng (Guangzhou), Jian-Hua Lu (Guangzhou), Shu-Qing Wang (Qiqihaer), Li Zhao (Beijing), Hua Zhang (Qingdao), Peng-Fei Yu (Pingdu), Xiao-Ping Hui (Shanghai), Shi-Ping Liu (Nanchong), Xi-Zhou Zhang (Yibin), Xiao-Dan $\mathrm{Gu}$ (Chengdu), Zhao-Xia Zan (Langfang).

\section{Acknowledgment}

This study was supported by a grant from Boehringer Ingelheim.

\section{Disclosure}

The authors report no conflicts of interest in this work.

\section{References}

1. Lip GY, Tse HF, Lane DA. Atrial fibrillation. Lancet. 2012;379(9816): 648-661.

2. Go AS, Hylek EM, Phillips KA, et al. Prevalence of diagnosed atrial fibrillation in adults: national implications for rhythm management and stroke prevention: the AnTicoagulation and Risk Factors in Atrial Fibrillation (ATRIA) Study. JAMA: the journal of the American Medical Association. 2001;285(18):2370-2375.

3. Kazemian P, Oudit G, Jugdutt BI. Atrial fibrillation and heart failure in the elderly. Heart Fail Rev. 2012;17(4-5):597-613.

4. Lip GY. Using the CHA(2)DS(2)-VASc score for stroke risk stratification in atrial fibrillation: a clinical perspective. Exp Rev Cardiovasc Ther. 2013;11(3):259-262.

5. Kirchhof P, Lip GY, Van Gelder IC, et al. Comprehensive risk reduction in patients with atrial fibrillation: emerging diagnostic and therapeutic options. Executive summary of the report from the 3rd AFNET/EHRA consensus conference. Thromb Haemost. 2011;106(6):1012-1019.

6. Hylek EM, D’Antonio J, Evans-Molina C, Shea C, Henault LE, Regan S. Translating the results of randomized trials into clinical practice: the challenge of warfarin candidacy among hospitalized elderly patients with atrial fibrillation. Stroke. 2006;37(4):1075-1080.

7. Mant J, Hobbs FD, Fletcher K, et al. Warfarin versus aspirin for stroke prevention in an elderly community population with atrial fibrillation (the Birmingham Atrial Fibrillation Treatment of the Aged Study, BAFTA): a randomised controlled trial. Lancet. 2007;370(9586):493-503.
8. Miyasaka Y, Barnes ME, Gersh BJ, et al. Secular trends in incidence of atrial fibrillation in Olmsted County, Minnesota, 1980 to 2000, and implications on the projections for future prevalence. Circulation. 2006; 114(2):119-125.

9. Camm AJ, Kirchhof P, Lip GY, et al. Guidelines for the management of atrial fibrillation: the Task Force for the Management of Atrial Fibrillation of the European Society of Cardiology (ESC). Eur Heart J. 2010;31(19):2369-2429.

10. Lip GY, Lim HS. Atrial fibrillation and stroke prevention. Lancet Neurol. 2007;6(11):981-993.

11. Van Staa TP, Setakis E, Di Tanna GL, Lane DA, Lip GY. A comparison of risk stratification schemes for stroke in 79,884 atrial fibrillation patients in general practice. J Thromb Haemost. 2011;9(1):39-48.

12. Friberg L, Rosenqvist M, Lip GY. Evaluation of risk stratification schemes for ischaemic stroke and bleeding in 182,678 patients with atrial fibrillation: the Swedish Atrial Fibrillation cohort study. Eur Heart J. 2012;33(12):1500-1510.

13. Camm AJ, Lip GY, De Caterina R, et al. 2012 Focused update of the ESC Guidelines for the management of atrial fibrillation: an update of the 2010 ESC Guidelines for the management of atrial fibrillation. Developed with the special contribution of the European Heart Rhythm Association. Eur Heart J. 2012;33(21):2719-2747.

14. WolfPA, D'Agostino RB, Belanger AJ, Kannel WB. Probability of stroke: a risk profile from the Framingham Study. Stroke. 1991;22(3):312-318.

15. Gallagher AM, Rietbrock S, Plumb J, van Staa TP. Initiation and persistence of warfarin or aspirin in patients with chronic atrial fibrillation in general practice: do the appropriate patients receive stroke prophylaxis? J Thromb Haemost. 2008;6(9):1500-1506.

16. Nantsupawat T, Nugent K, Phrommintikul A. Atrial fibrillation in the elderly. Drugs Aging. 2013;30(8):593-601.

17. Guo Y, Wu Q, Zhang L, et al. Antithrombotic therapy in very elderly patients with atrial fibrillation: is it enough to assess thromboembolic risk? Clin Interv Aging. 2010;5:157-162.

18. Quilliam BJ, Lapane KL. Clinical correlates and drug treatment of residents with stroke in long-term care. Stroke. 2001;32(6):1385-1393.

19. Granger CB, Alexander JH, McMurray JJ, et al. Apixaban versus warfarin in patients with atrial fibrillation. $N$ Engl J Med. 2011;365(11):981-992.

20. Patel MR, Mahaffey KW, Garg J, et al. Rivaroxaban versus warfarin in nonvalvular atrial fibrillation. N Engl J Med. 2011;365(10):883-891.

21. Eikelboom JW, Wallentin L, Connolly SJ, et al. Risk of bleeding with 2 doses of dabigatran compared with warfarin in older and younger patients with atrial fibrillation: an analysis of the randomized evaluation of long-term anticoagulant therapy (RE-LY) trial. Circulation. 2011; 123(21):2363-2372.

22. Bourbeau J, Bartlett SJ. Patient adherence in COPD. Thorax. 2008; 63(9):831-838.

23. Lopez CM, House-Fancher MA. Management of atrial fibrillation in patients with chronic obstructive pulmonary disease. J Cardiovasc Nurs. 2005;20(2):133-140.
Clinical Interventions in Aging

\section{Publish your work in this journal}

Clinical Interventions in Aging is an international, peer-reviewed journal focusing on evidence-based reports on the value or lack thereof of treatments intended to prevent or delay the onset of maladaptive correlates of aging in human beings. This journal is indexed on PubMed Central, MedLine,
Dovepress

CAS, Scopus and the Elsevier Bibliographic databases. The manuscript management system is completely online and includes a very quick and fair peer-review system, which is all easy to use. Visit http://www.dovepress. com/testimonials.php to read real quotes from published authors. 